practice and it is hoped that should the value of the preparation in this branch be further proved, it will be made up in smaller quantities, such as 1 c.c., which would be ample.

\title{
Summary
}

A short preliminary report is given on the use of thrombin for the quick and efficient sealing of conjunctival wounds, without the use of sutures. Attention is also drawn to its possible use as an ophthalmic haemostatic.

\section{SURVEY OF THE TREATMENT OF TRAUMATIC CORNEAL ULCER*† \\ 1941-1944, Royal Hospital, Sheffield}

BY

\section{ARTHUR SMITH}

SHEFFIELD

THIS paper consists of a restricted statistical and clinical survey of a consecutive series of cases of corneal ulcer which were severe enough to demand in-patient treatment in the Royal Hospital during the four years from 1941 to 1944 .

I have confined my attention to traumatic ulcers in view of their ease of comparison and similarity in aetiology, and particularly because Sheffield claims a high incidence of this type of ulcer. I lay no claim to an investigation similar to that of the W. H. Ross Foundation of Scotland, so I cannot give you the elaborate scientific and pathological detail characteristic of deliberate scientific research. The data are based entirely on the individual case records made as a routine during a patient's stay in this hospital. It can be stated with confidence, however, that periodical surveys of clinical records are valuable in retrospect and in helping to preserve a sense of proportion and perspective when estimating the results of treatment of one's own cases. But comparisons are highly stimulating at times and so I have presumed to attempt a comparison of the final visual acuities from this series of cases with those published in 1942 by the Ross Foundation.

During the years 1941 to 1944351 cases of corneal ulcer were admitted to the Royal Hospital for in-patient theatment. Of these 89 were of spontaneous origin (at least they gave no history of trauma) and 262 were traumatic. \footnotetext{
1945.

Read at a meeting of the North of England Ophthalmological Society, April 21, 
The following graph (a) enables a comparison to be made of this incidence with that of the previous five years, 1936 to 1940 . The spontaneous ulcers average 24 cases a year and the incidence fluctuates between 18 and 35 yearly. The traumatic ulcers average 53 cases a year and the incidence shows a marked rise in 1942 and 1943 ranging from 34 in 1937 to 84 in 1942.

(a)-Annual incidence of cases admitted to hospital, 1936 to 1944

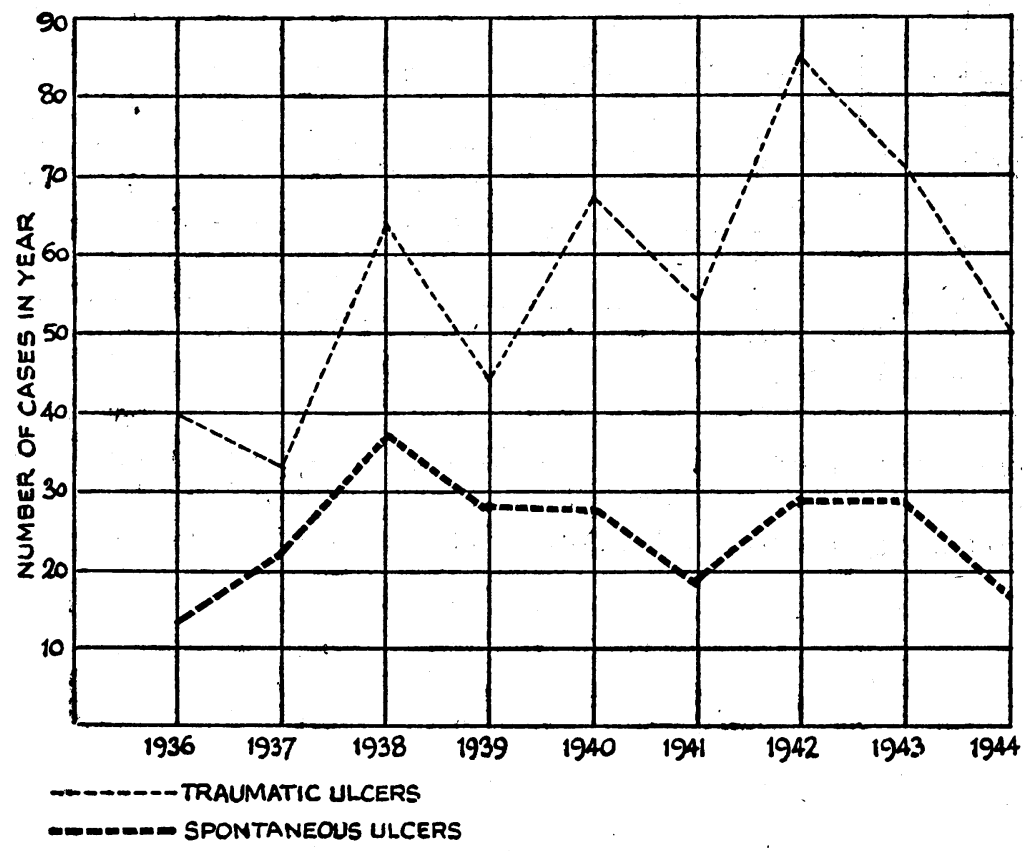

I have classified the traumatic ulcers that were seen in this department as (a) hypopyon, (b) less severe, $(c)$ slight.

The last group were treated in the Out-patient Department, the others were admitted, so this survey deals entirely with the hypopyon and less severe groups. The incidence of these two groups during the nine years 1936 to 1944 , is shown in graph $(b)$. It is seen that the incidence of hypopyon ulcers remains much the same throughout the nine years, but there is a greater fluctuation in the incidence of the less severe cases, a fluctuation which corresponds with that of the graph for traumatic ulcers in general (a). A total of 79 hypopyon ulcers and 183 less severe ulcers were treated as in-patients during 1941 to 1944 .

At this point it is worth noting the effect of occupation on the incidence of traumatic ulcers. A detailed analysis of occupations could not be made from the in-patient records, but I have 
(b) TRAUMatic UlCERS-Incidence of hypopyon and less severe ulcers, 1936 to 1944

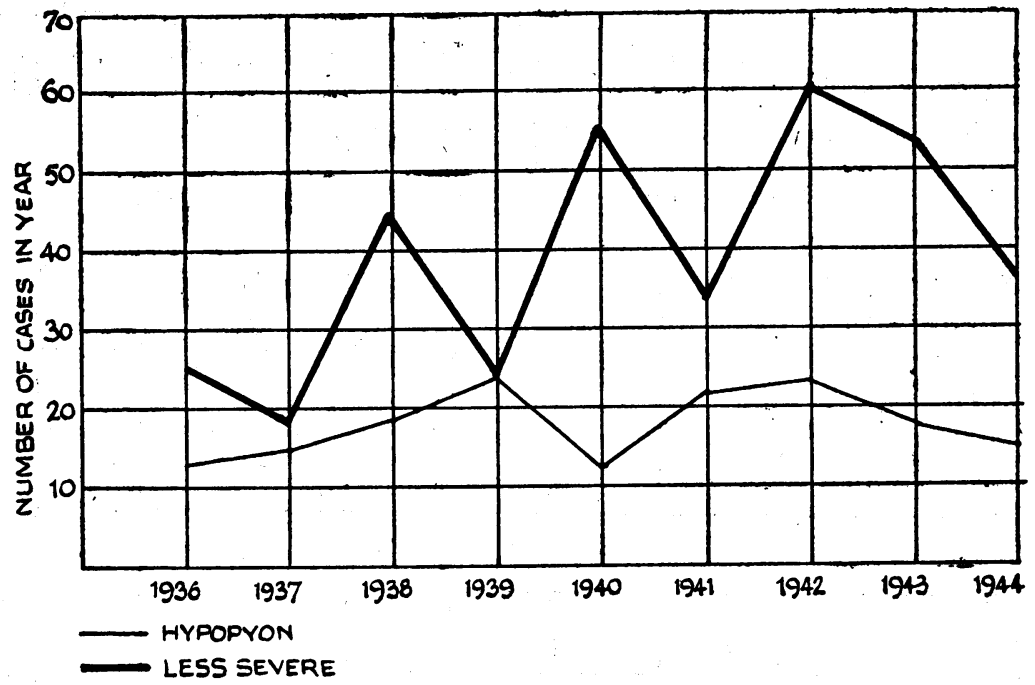

attempted to analyse the occupations of those who attended for the follow-up examination. The following table $(c)$ will help in appreciating the now well known fact that miners seem unusually

(c) TRAumatic Ulcers-Occupational incidence in 131 cases.

\begin{tabular}{lr|c|c}
\hline \multicolumn{2}{c|}{ Occupation } & Hypopyon & Less severe \\
\hline & & & \\
\hline Miners $\ldots$ & $30^{\circ} 4$ per cent. & $18^{\circ} 9$ per cent. \\
Steelworkers & $26^{\circ} 8$ per cent. & $32{ }^{\circ} 4$ per cent. \\
Grinders $\ldots$ & $7^{\circ} 1^{\prime}$ per cent. & 9.5 per cent. \\
\hline
\end{tabular}

liable to hypopyon ulcers and form 30.4 per cent. of the cases in this follow-up series. Steelworkers in general make up 26.8 per cent. of the cases, and steel-grinders form only $7 \cdot 1$ per cent.

A slightly different result appears in the analysis of the less severe ulcers. Here steelworkers predominate with an incidence of 32.4 per cent., miners form only 18.9 per cent. and grinders 9.5 per cent. of the cases.

In both groups I expected the incidence to be much higher among grinders in view of the frequency of this occupation in the Sheffield steel industry. 
The treatment of these patients can be described under two headings (a) General, (b) Local.

General treatment.-All the hypopyon and nearly all the less severe cases were given Coley's fluid, adults being given 7 minims and 10 minims on successive days. The resulting pyrexia varied between 100 and 103 degrees in most cases. Coley's fluid consists of 600 millions of streptococci per c.c. with $0 \cdot 25$ per cent. B. prodigiosus protein and 13.3 per cent. of glycerine. It has been used exclusively in the Royal Hospital, Sheffield, for these ulcer cases since 1935 .

In July, 1939, this pyrexial therapy was combined with the simultaneous internal administration of sulphonamides, and we have found the combination effective in most cases since. M. and B. 693 was in regular use until. March, 1944, when sulphathiazole, and later, sulphamethazine became popular. The initial dose of 2 grams was followed by 1 gram four hourly for 2 days and then 1 gram thrice daily up to a total amount of 30 grams.

In debilitated cases treatment was augmented by vitamin therapy.

Local treatment.-This was also changed from time to time. Guttae atropine and scarlet red in cod liver oil was used for some time before this series began and until September, 1943, when the scarlet red was omitted. After July, 1944, until December, guttae atropine and 20 per cent. albucid soluble was used almost exclusively. Since then we have used an emulsion of 30 per cent. albucid soluble in cod liver oil, the atropine at first being instilled separately owing to the incompatibility of the alkaloid with the unbuffered solution, of sulphacetamide. We are now using in this emulsion a buffered albucid solution with a $\mathrm{pH}$ of 7.4 to avoid conjunctival irritation and to allow atropine to be accurately dispensed with it. Briefly, the aim is to get a more prolonged and effective absorption of the albucid as the globules, which are about 2 or 3 times the size of milk-fat globules, break up leaving behind a continuous film of oil protecting the surfaces. This form of local treatment was introduced by Mr. Gordon Mackie, the visiting Honorary Ophthalmic Surgeon to the Royal Hospital.

Carbolization is still, I believe, the recognised local treatment for severe corneal ulcer. When I first came to Sheffield in 1941 I was greatly interested to find that the late Dr. P. J. Hay had ceased to carbolize corneal ulcers however severe. Patients recovered just as quickly and with, I think, less scarring than if they had been carbolized. In fact the visual results were very good and no worse than a subsequent small series of carbolized ulcers which were, I must admit, very severe. In the past it seemed logical to carbolize severe corneal ulcers on the assumption 
that infective debris was thereby cleared away, leaving the floor of the ulcer protected by a phenol-coagulum which was likely to inhibit further growth of organisms. In the light of new remedies, however, such as the sulphonamides and penicillin carbolization may have become unnecessary.

No operative interference was attempted except in one case demanding a paracentesis for removal of a large fibrinous hypopyon and in four other cases which were eviscerated. Two of these had perforated corneal ulcers on admission and the others perforated subsequently despite carbolizing.

In estimating the results of this treatment it may be some guide to consider :-

(a) The stay in hospital.

(b) The time the hypopyon took to absorb.

(c) Complications.

(d) The visual acuity 4 months or later after discharge.

The time off work could not be accurately estimated from the records.

(a) The stay in hospital.-The average stay in hospital varied considerably according to type of ulcer and the age of the patient. Using the same classification mentioned above, I have worked out the average stay in hospital for each group over the period of nine years from 1936 to 1944 . The result is shown in the following table $(d)$ but is more easily appreciated with the help of the graph $(e)$.

(d)

\begin{tabular}{c|c|c}
\hline \multirow{2}{*}{ Year } & \multicolumn{2}{|c}{ Days in hospital } \\
\cline { 2 - 3 } & Hypopyon & Less severe \\
\hline 1936 & $17{ }^{\circ} 8$ & $15^{\circ} 0$ \\
1937 & $20^{\circ} 8$ & $11^{\circ} 7$ \\
1938 & $19^{\circ} 8$ & $12^{\circ} 4$ \\
1939 & $20^{\circ} 1$ & $13^{\circ} 0$ \\
1940 & $17^{\circ} 8$ & $10^{\circ} 7$ \\
1941 & $14^{\circ} 9$ & $9 \cdot 2$ \\
1942 & $15^{\circ} 9$ & 8.6 \\
1943 & $13^{\circ} 5$ & $8^{\circ} 7$ \\
1944 & $12^{\circ} 5$ & 7.5 \\
\hline
\end{tabular}


(e) TRAUmatic UlCeRs-Average stay in hospital, 1936 to 1944

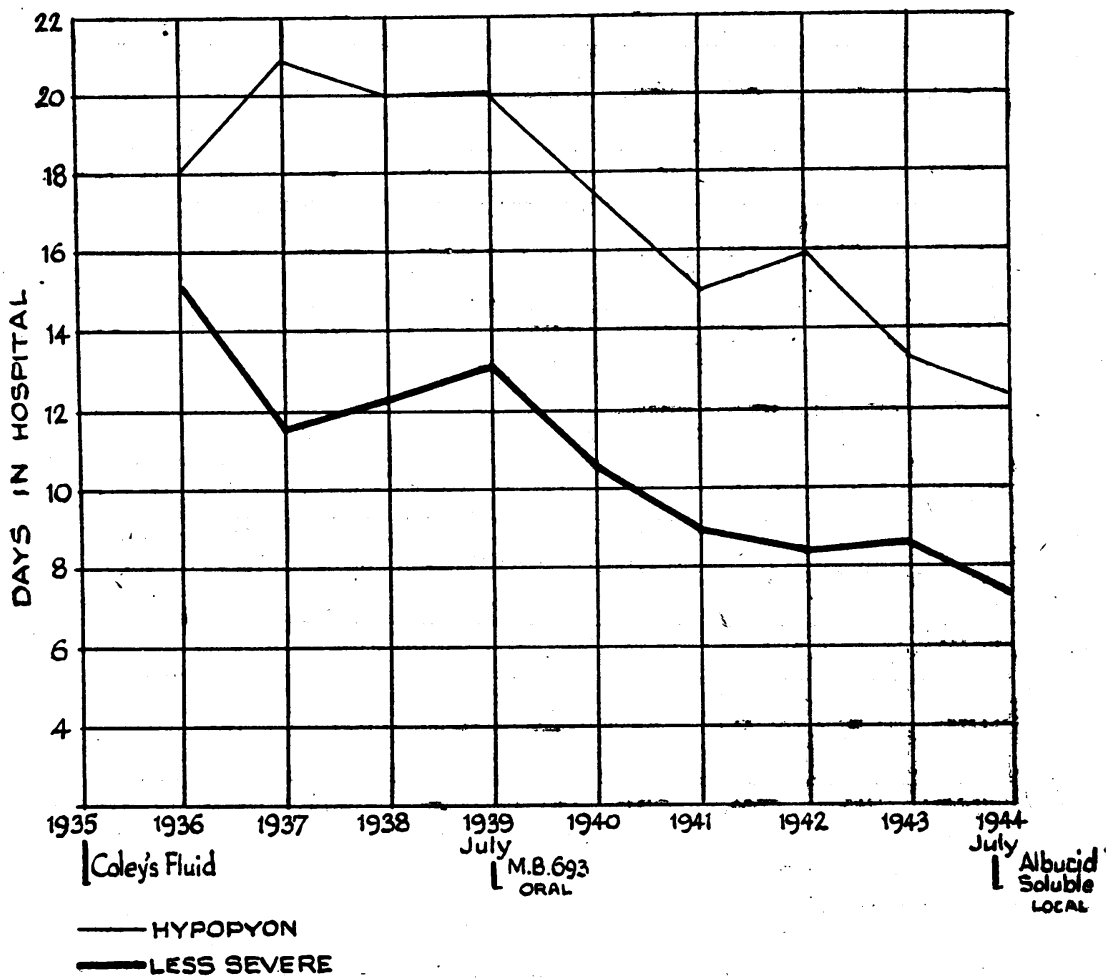

It will be observed that in hypopyon ulcers the average stay was in the region of 19 to 20 days until sulphapyridine became a routine treatment. From that year a sudden fall is noticed in these averages, first to 15 days in 1941 and in the last two years to 13.5 and 12.5 days respectively.

The less severe ulcers show a similar change, only the stay in hospital falls from 15 to $7 \cdot 5$. days.

The age of the patient was another interesting factor influencing the stay in hospital. The graph $(f)$ will give an idea of the average stay for the various age groups. Hypopyon ulcers under 45 years averaged 9.5 days, then rose to 13 days in the 65 age group and above that age soared up to 30 days. Less severe ulcer cases averaged a fairly constant figure between 8 and 9.5 days for all age groups.

(b) The time the hypopyon took to absorb.-This was fairly constant with certain exceptions. It was recorded in only 34 case records, however, but even this small number may give 


\section{(f)-Average days in hospital in relation to age groups}

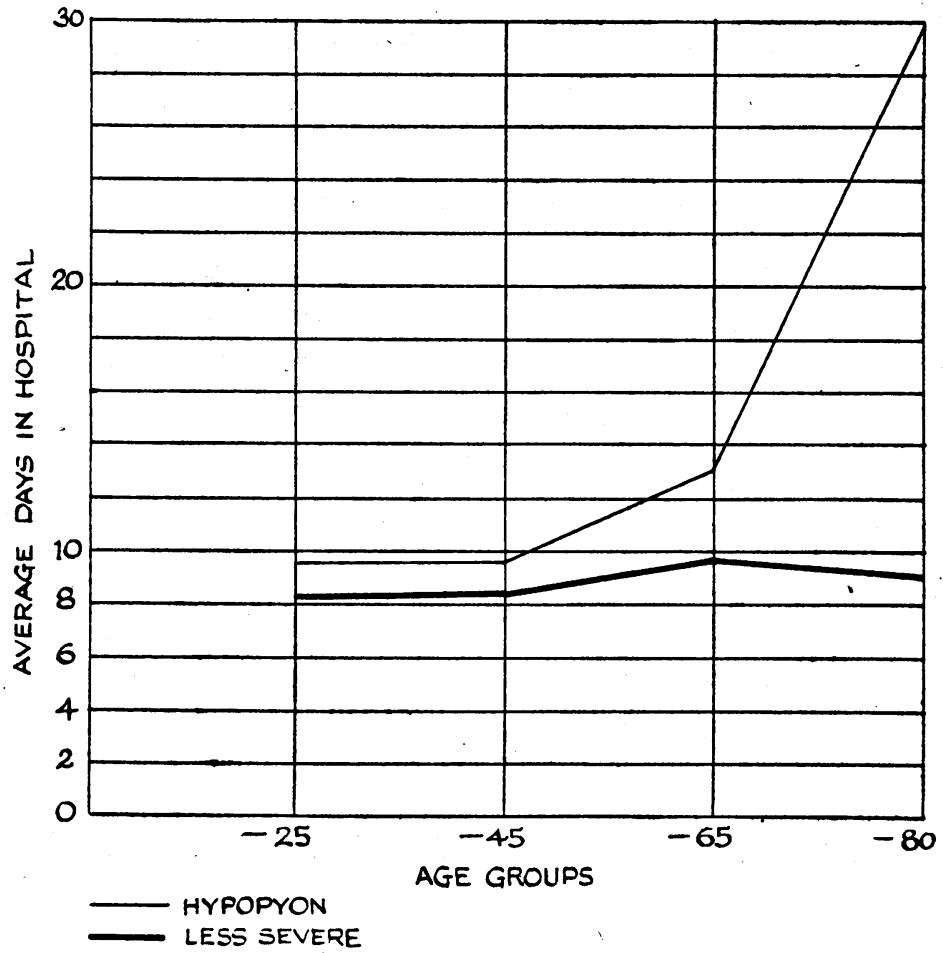

some idea of the value of the treatment. One small group of 4 cases had an average period of 16 days. These were very severe cases and the patients were debilitated and in the middle and older age groups.

The large group of 30 cases showed an average period of 2 days, varying from 15 hours to 3 days.

(c) Complications.-These consisted of the four cases of endophthalmitis I have already mentioned together with the paracentesis case, which, however, healed remarkably well and was discharged from hospital with a vision of $6 / 60$.

(d) Visual acuity.-This is the most effective standard on which to assess the value of any particular treatment. I have attempted to follow up all these 262 cases in order to test their final visual acuities. The response though not as satisfactory as was hoped provides enough data on which to work. Where necessary arrors of refraction were corrected.

Hypopyon ulcers. Out of a total of 79 cases sent for, 56 attended for examination, 70.9 per cent. 
(g) HYPOPYON ULCERS-Visual acuity in relation to age groups

\begin{tabular}{lr|r|r|r|r|r|r|r|r|r|r|r|r}
\hline \multicolumn{2}{l|}{ Age group } & $6 / 4$ & $6 / 5$ & $6 / 6$ & $6 / 9$ & $6 / 12$ & $6 / 18$ & $6 / 24$ & $6 / 36$ & $6 / 60$ & $\begin{array}{c}\mathrm{H} \mathrm{M} \\
\text { and } \\
\mathrm{PL}\end{array}$ & $\mathrm{Nil}$ & \\
\hline 25 & $\ldots$ & 2 & 2 & 4 & - & 3 & - & - & - & - & - & - & - \\
\hline 45 & $\ldots$ & 3 & 5 & 5 & 2 & 3 & - & 1 & - & 1 & - & - & - \\
65 & $\ldots$ & - & 2 & 4 & 5 & 4 & 2 & 1 & - & 1 & - & 3 & - \\
80 & $\ldots$ & - & - & - & - & - & - & - & - & - & 2 & 1 & - \\
\hline \multicolumn{2}{l}{ Total cases } & 5 & 9 & 13 & 7 & 10 & 2 & 2 & - & 2 & 2 & 4 & 56 \\
\hline \multicolumn{2}{l}{ Per cent. } & 9 & 16 & 23 & 12.5 & 18 & 3.6 & 3.6 & - & 3.6 & 3.6 & 7 & 100 \\
\hline
\end{tabular}

It will be seen from this table that 8 cases, $14 \cdot 3$ per cent. had no useful vision (i.e., $6 / 60$ or less); 44 cases, 78.5 per cent. had a vision of $6 / 12$ or better ; 27 cases, 482 per cent. had a vision of $6 / 6$ or better.

These results compare favourably with the Glasgow and Edinburgh series of follow-up cases, totalling 86 and 229 cases respectively which included only a proportion of hypopyon ulcers. Of the 350 Edinburgh cases approximately 51.0 per cent. were hypopyon ulcers, but it is not stated what percentage of the followup cases were hypopyon ulcers. The following table $(h)$ will not, I hope; prove an unfair comparison.

(h)

\begin{tabular}{l|c|c|c|c}
\hline & $\begin{array}{c}6 / 12 \text { or } \\
\text { better }\end{array}$ & $\begin{array}{c}\text { No useful } \\
\text { vision }\end{array}$ & $\begin{array}{c}\text { Total of } \\
\text { Follow-up } \\
\text { cases }\end{array}$ & Severity \\
\hline Glasgow .. & 27.9 & 33.7 & 87 & Mixed \\
Edinburgh & 53.2 & $20^{\circ} 5$ & 229 & Mixed \\
Sheffield... & $78^{\circ} 5$ & 14.3 & 56 & Hypopyon \\
\hline
\end{tabular}


(i) LESS SEVERE ULCERS.-Visual acuity in relation to age groups.

\begin{tabular}{|c|c|c|c|c|c|c|c|c|c|c|c|c|}
\hline Age group & $6 / 4$ & $6 / 5$ & $6 / 6$ & $6 / 9$ & $6 / 12$ & $6 / 18$ & $6 / 24$ & $6 / 36$ & $6 / 60$ & $\begin{array}{l}\mathrm{HM} \\
\text { and } \\
\mathrm{PL}\end{array}$ & Nil & \\
\hline$\ldots$ & 5 & 7 & 3 & - & - & - & - & - & - & - & - & - \\
\hline$\ldots$ & 6 & 15 & 4 & 8 & 1 & 1 & $=$ & - & - & - & - & - \\
\hline 65 & 3 & 12 & 1 & 3 & 2 & 2 & - & - & - & - & - & - \\
\hline$\ldots$ & - & 1 & - & - & 1 & - & - & - & - & - & - & - \\
\hline Total cases & 14 & 35 & 8 & 11 & 4 & 3 & - & - & - & - & - & 75 \\
\hline Per cent. & $18 \cdot 7$ & 46.6 & 10.7 & $14 \cdot 7$ & $5 \cdot 3$ & 4 & - & - & - & - & - & 100 \\
\hline
\end{tabular}

Less severe ulcers. Out of a total of 183 only 75 attended for re-examination. This was a disappointing response, but their final visual results which I show in this table (i) may form some basis on which to assess the visual result of the series as a whole.

57 cases, 76 per cent. had $6 / 6$ or better.

72 cases, 96 per cent. had $6 / 12$ or better.

4 cases, 5 per cent. had $6 / 18$.

Of cases with no useful vision there were none.

In conclusion I will only mention two aspects of treatment which seem to me significant in this analysis.

(a) The marked drop in the number of days in hospital after the internal administration of sulphonamides became a routine treatment.

(b) The simultaneous combination of pyrexial therapy (Coley's fluid) with sulphonamides seems very effective, and may largely account for the excellent visual results obtained, particularly in the hypopyon group of cases.

The local sulphonamide therapy has not been employed for a sufficient length of time on which to formulate any reliable conclusions.

My thanks are due to Mr. Gordon Mackie and Miss Hatherley for permission to publish th's analysis of their in-patient records. I must also acknowledge my indebtedness to Dr. David Tolmie for his assistance with the follow-up cases and for his careful checking of my statistical results.

\section{REFERENCE}

Dickson, R. M.-Brit. Jl. Ophthal., Vol. XXVI, p. 529, December, 1942. 